\title{
Prevalence and Transmission of Fusarium moniliforme: A Seed Borne Pathogen of Rice
}

\author{
M S Hossain ${ }^{1 *}$, M A Ali $^{2}$, M A I Khan ${ }^{3}$ and S Maniruzzaman ${ }^{4}$
}

\begin{abstract}
Fusarium moniliforme is one of the major seed borne pathogen of rice in Bangladesh that causes significant yield loss. To observe the incidence and transmission of this pathogen, farmers saved seeds and seeds from BADC were collected and the pathogens were detected by blotter method. The prevalence of the F. moniliforme varied according to locations and seasons. The highest $18 \%$ of seed infection was recorded in Boro seeds of Netrakona district and the lowest $2 \%$ was in Gazipur district. The Embryonal end of the seed is the most preferable site of the infection. F. moniliofrme successfully transmitted from seed to seedling and the transmission is high when pre- sprouted seed sown on the puddled seed bed. The study recommended that before planting season, seeds should be tested and treated when necessary to minimize spread of the pathogen.
\end{abstract}

Key words: F. moniliforme, rice seed, transmission, sporulation, incidence.

\section{INTRODUCTION}

Rice, the important cereal crops of Bangladesh, is grown extensively in all over the country. The crop is affected with as many as 32 different diseases in Bangladesh. Of which, 10 documented major diseases and five of them are seed borne (Miah and Shahjahan, 1987). Among the major seed borne pathogens of rice, F. moniliforme Sheldon (causal agent of bakanae disease) is quite serious. Under favourable conditions, it causes substantial damage and as high as $95.4 \%$ yield loss has been estimated in India and in Bangladesh upto $26.7 \%$ yield loss recorded due to bakanae disease (Singh and Sunder, 1997: Latif et al, 2006). During the present study, a severe infection of bakanae disease of rice observed in different regions of Bangladesh such as Dinajpur, Habiganj, Cumilla, Netrakona and Gazipur. Infected seed is the main means of such spreading the disease from field to field; because the seed-borne inocula provide initial foci for seedling infection and subsequently infection taken place in the main field (Nath et al. 1970; Winter et al. 1974). Infected plants in the field that reach heading produce enormous amount of inocula which infect the developing grains results in deep infection on the seed (Kim, 1981). From Bangladesh Mia and Mathur (1983) tested seed health of 75 rice seed sample from different parts and observed more than $90 \%$ samples infected with the F. moniliforme and the extent of infection of $1.0-20.16 \%$ (Hossain, 2002; Momotaz, 2005).

Seed is one of the basic elements for crop production and help to increase agricultural productivity. When seed has good health and physical qualities, farmers have greater prospects of producing a good crop (Miva et al., 2017). The present investigation has been carried out to establish baseline information on quality of farmers saved rice seed in respect of bakanae pathogen, to enhanced strategy of yield improvement. This is important as many farmers use own stored seeds for the next cropping season, though seed borne diseases can be transferred easily and hence other quality attributes may be sub-standard. Proper assessment of the quality of seed, stored by farmers from their previous crop will establish the broad picture of seed quality of locally produced rice as compared to quality declared seed (BADC seed). Therefore, this paper aims to evaluate the incidence of F. moniliforme in

\footnotetext{
${ }^{1}$ Chief Scientific Officer (Current Charge) and Head, Training Division, BRRI, Gazipur, Bangladesh, ${ }^{2}$ Professor, Department of Plant Pathology, BAU, Maymensingh, Bangladesh, ${ }^{3}$ Principal Scientific Officer, Plant Pathology Division, BRRI, Gazipur, Bangladesh, ${ }^{4}$ Scientific Officer, Plant Breeding Division, BRRI, Gazipur, Bangladesh.

*Corresponding author's E-mail:sahadatbrri@yahoo.com
} 
farmers saved rice seeds in some selected districts of Bangladesh and to find its transmission from seeds to seedlings.

\section{MATERIALS AND METHODS}

A total of 326 seed samples of farmer's saved seeds in each season (Aus, Aman, Boro) from five locations viz Cumilla, Netrakona, Dinajpur, Gazipur and Habiganj were collected. Samples of BADC were collected from its seed processing centers (SPC) located all over the country. The quantity of each sample was about $500 \mathrm{~g}$. Samples were kept in brown paper bag, labeled properly and preserved in a refrigerator at $5-8^{\circ} \mathrm{C}$ for subsequent use.

The collected samples were tested by blotter method to detect $F$. moniliforme following International Rules for Testing Seed Health (ISTA, 2000). Three layers of filter papers (Whatman No.1) soaked in sterilized water was placed at the bottom of a nine $\mathrm{cm}$ diameter plastic petridish. Then 25 seeds were placed on the filter paper in each plate. For each sample 400 seeds were tested. The petridishes containing the seeds were incubated at $25 \pm 1^{\circ} \mathrm{C}$ under alternating cycle of 12/12 hours near NUV light and darkness for seven days. After incubation, the seeds were examined under stereobinocular microscope. A temporary slide was prepared and observed under compound microscope to confirm the pathogen F. moniliforme according to Burgess et al., 1994. Number of seeds on which F. moniliforme grew was recorded. Data were converted into percentage of seed-borne infection. Seed infection between farmers saved seeds and BADC seeds were compared by using the paired t-test.

Detection of $F$. moniliforme in different seed grade. Bakanae infected rice seeds collected from farmer's field were grouped manually into different categories viz apparently healthy, discoloured filled grain, discoloured unfilled grain and unfilled grain with normal colour. From each category of seeds, 400 seeds were examined for $F$. moniliforme by blotter method and the methods described above. The fungi colony that grew out from the seeds were recorded after seven days of incubation. The data were analyzed and differences among the treatment means were compared following Duncans Multiple Range Test (DMRT).

Site of sporulation of $F$. moniliforme on infected seeds. During detection of $F$. moniliforme on seeds, observations were made on whether the seeds were germinated and infected. Infected seeds were examined. Fungus sporulation was observed in two sites of the seed i.e (a) embryonal end alone and (b) entire seed surface including embryonal end.

Transmission of $F$. moniliforme from seed to seedlings. Naturally infected seed samples of BR1 and BRRI dhan44 were used in this study. One week prior to the start of the seed transmission studies, seed infection percentage was determined. These two samples were stored at $5^{\circ} \mathrm{C}$ in a refrigerator after seed health testing and used for seed transmission studies.

A total of 48 plastic pots $(20 \times 12 \mathrm{~cm})$ were taken. Twenty-four pots were filled with sterilized soil and another 24 pots were filled with non-sterilized soil. Soil was sterilized following the methods described by Sunder and Satyavir, 1998. Infected seeds of rice variety BR1 and BRRI dhan 44 were used. One hundred seeds of each variety were sown in pot by using three different seeding methods and which were a) Dry seed sown on wet pot, b) Sprouted seed sown on wet pot, and c) Dry seed sown under moist soil. Complete covering of seeds was done by 1 to $1.5 \mathrm{~cm}$ layer of soil and then compressed by hand. The pots were arranged in a completely randomized block design with four replications for each treatment. The seedlings 
were examined for the presence of bakanae infected seedlings after seven days until four weeks. The data were analyzed and differences among the treatment means were compared following Duncans Multiple Range Test (DMRT).

\section{RESULTS}

Table 1 shows the occurrence of $F$. moniliforme in the seed samples of Aus, Aman and Boro seasons collected from different locations. In case of Aus seeds, 20 samples were tested from Dinajpur, 17 of them were infected with $F$. moniliforme. The pathogen was detected in 31 out of 34 samples of Habiganj. F. moniliforme was detected from eight samples of Cumilla. Number of infected samples was three and 10 in Netrakona and Gazipur, respectively. The percentage of infection in different samples of Dinajpur, Habiganj, Cumilla, Netrakona and Gazipur districts was 85, 91, 54, 25 and 47, respectively. During Aman season, about 42 percent of the samples were infected in Dinajpur and $87 \%$ in Gazipur. But $100 \%$ samples of the Cumilla and $90 \%$ samples of Habiganj were infected by F. moniliforme. Table 1 also shows the prevalence of $F$. moniliforme in the seed samples of different locations during Boro season. The pathogen was detected from 30 out of 36 samples of Habiganj. Thirty-three samples were tested from Dinajpur, 19 of them were infected with F. moniliforme. The pathogens were detected from 11 out of 15 samples of Cumilla. F. moniliforme was detected from seven samples of Gazipur. The percentage of sample infection was high $88 \%$ in Netrakona followed by $83 \%$ in Habiganj. It was 58,73 and $47 \%$ respectively in Dinajpur, Cumilla and Gazipur district.

Figure 1 presents the average infection of $F$. moniliforme in different locations during Aus, Aman and Boro seasons. During Aus season, maximum infection of $F$. moniliforme was found in the seeds collected from Habiganj and Dinajpur district. The minimum (1.91\%) infection was recorded in Gazipur district. The infection of the pathogen in the seeds of Cumilla and Netrakona were almost similar. Infection of F. moniliforme also influenced by different locations during Aman season. The maximum infection was found in seeds collected from Cumilla. The infection was almost similar in the seeds of Gazipur, Habiganj and Netrakona. The minimum infection was found in seeds collected from Dinajpur. Considering Boro season, the highest infection was recorded in the seeds of Netrokona and Habiganj. The infection in the seeds of Gazipur and Cumilla were 8.93, $4.06 \%$ respectively. The lowest infection was found in the seeds of Dinajpur district.

Table 1. Incidence of F. moniliforme in the collected seed samples of Aus, Aman and Boro season.

\begin{tabular}{l|c|c|c|c|c|c|c|c|c}
\hline & \multicolumn{3}{|c|}{ Aus } & \multicolumn{3}{c|}{ Aman } & \multicolumn{3}{c}{ Boro } \\
\hline Location & $\begin{array}{c}\text { No. of } \\
\text { sample }\end{array}$ & $\begin{array}{c}\text { No. of } \\
\text { sample } \\
\text { infected }\end{array}$ & $\begin{array}{c}\% \\
\text { sample } \\
\text { infected }\end{array}$ & $\begin{array}{c}\text { No. of } \\
\text { sample }\end{array}$ & $\begin{array}{c}\text { No. of } \\
\text { sample } \\
\text { infected }\end{array}$ & $\begin{array}{c}\% \\
\text { sample } \\
\text { infected }\end{array}$ & $\begin{array}{c}\text { No. of } \\
\text { sample }\end{array}$ & $\begin{array}{c}\text { No. of } \\
\text { sample } \\
\text { infected }\end{array}$ & $\begin{array}{c}\% \\
\text { sample } \\
\text { infected }\end{array}$ \\
\hline Dinajpur & 20 & 17 & 85 & 24 & 17 & 42 & 33 & 19 & 58 \\
Habiganj & 34 & 31 & 91 & 29 & 26 & 90 & 36 & 30 & 83 \\
Cumilla & 15 & 8 & 54 & 22 & 22 & 100 & 15 & 11 & 73 \\
Netrakona & 12 & 3 & 25 & 15 & 7 & 47 & 24 & 21 & 88 \\
Gazipur & 17 & 10 & 47 & 15 & 13 & 87 & 15 & 7
\end{tabular}



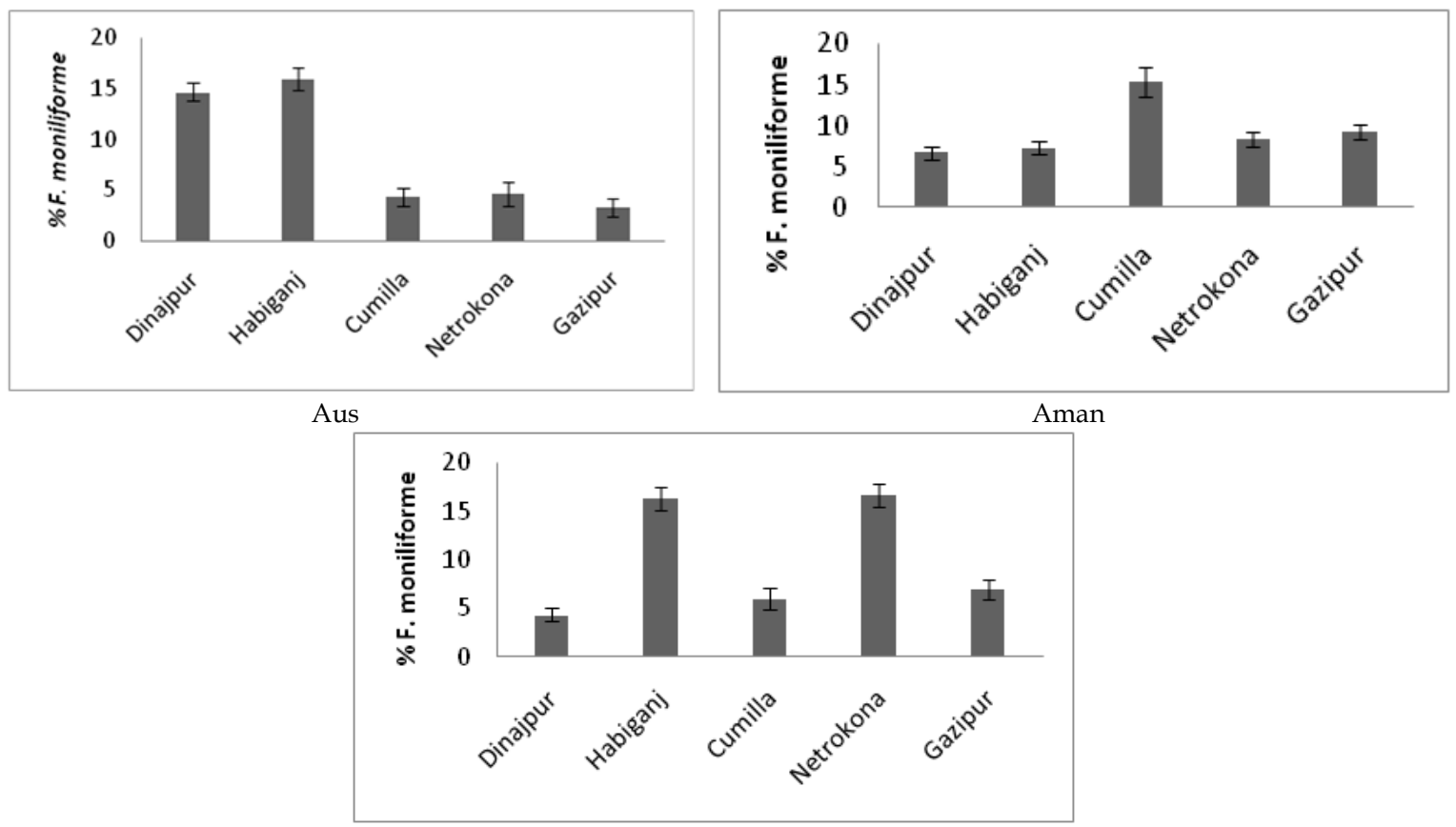

Boro

Fig. 1. Seed-borne infection of F. moniliforme in different locations during Aus, Aman and Boro seasons.

Table 2 shows the occurrence of $F$. moniliforme in rice seeds of different seed sources. Irrespective of growing season, seed infection was significantly higher in farmers' seeds compared to BADC seeds. The highest $7.61 \%$ infection was found in farmers seeds and it was 3.74\% in BADC seeds during Aus season. During Aman and Boro season the seed infection of F. moniliforme was $8.75 \%$ and $9.01 \%$ in case of farmer's seeds, respectively. It was $5.42 \%$ and $2.72 \%$ in BADC seeds.
It is evident from Figure 2 that the maximum infection in farmer's seeds was found in Habiganj and minimum in Gazipur. There was $8.20 \%$ seed infection in Netrakona. The incidence of $F$. moniliforme in Dinajpur and Cumilla was comparable. Incidence of $F$. moniliforme in BADC seeds was low in Gazipur but high in Habiganj. The incidence of pathogen in BADC seeds collected from Dinajpur, Netrakona and Gazipur was almost similar.

Table 2. Percentage of seed-borne infection of F. moniliforme in different seed sources.

\begin{tabular}{l|c|c|c|c}
\hline \multirow{2}{*}{ Seed source } & \multicolumn{3}{|c|}{ Percent infection } & \multirow{2}{*}{ Mean } \\
\cline { 2 - 4 } & Aus & Aman & Boro & 8.46 \\
\hline Farmers' seed & 7.61 & 8.75 & 9.01 & 3.96 \\
BADC seed & 3.74 & 5.42 & 2.72 & $*$ \\
\hline Significance & $*$ & $*$ & $*$ \\
\hline
\end{tabular}

\footnotetext{
* Significance at the $5 \%$ level by paired t-test.
}

14 Hossain et al. 


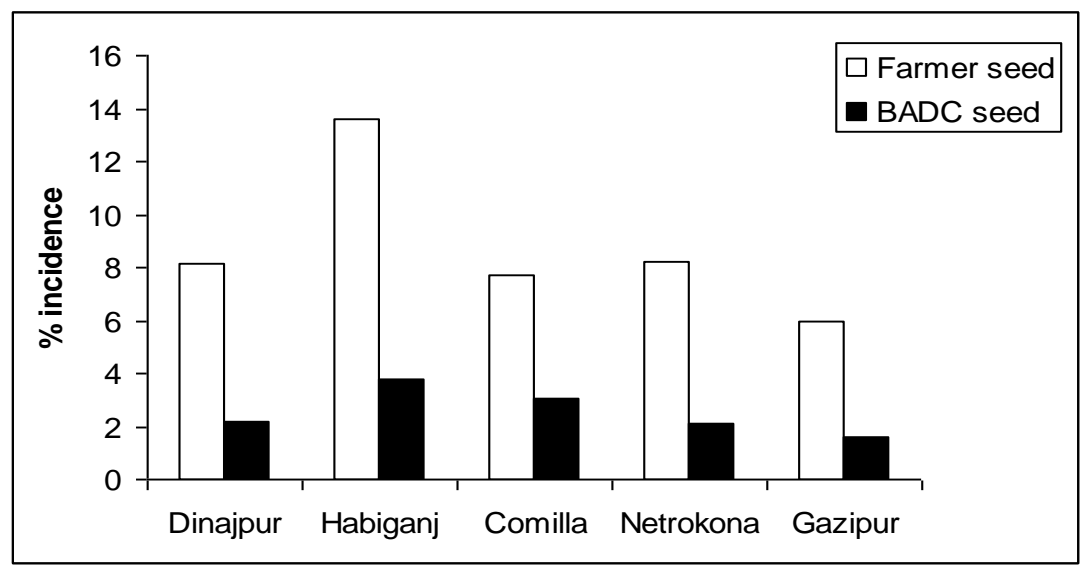

Fig. 2. Prevalence of $F$. moniliforme in the BADC and farmers' seeds of different locations.

Detection of $F$. moniliforme in different category of seeds. Table 3 presents seed-borne infection of F. moniliforme and other pathogens in different categories of seeds. The highest $74.75 \%$ incidence of F. moniliforme was present in discoloured unfilled grains. The lowest $17.50 \%$ incidence was found in apparently healthy seeds and the difference varies significantly. The pathogen was detected from $30.50 \%$ unfilled grains (without discolouration) and which was $31.50 \%$ from discoloured filled grains. The difference was insignificant. The highest incidence $(10.08 \%)$ of other pathogen was found in discoloured filled grain. Seed infection was $9.50 \%$ in discoloured unfilled grains. The lowest $6 \%$ incidence was found in apparently healthy looking seed. The incidence of other pathogen in unfilled grain (normal) was 7.42\% (Table 3).

Site of sporulation of $F$. moniliforme in rice seeds. F. moniliforme produced sporophores (sporulation) on the embryonal end of $12-16 \%$ of non-germinated seeds and $66-76 \%$ of germinated seeds. Conidiophores (sporulation) of the pathogen covered all over the upper surface of the $84-88 \%$ of the nongerminated and $25-34 \%$ of germinated seeds (Table 4). The mean sporulation of $F$. moniliforme was on the upper surface of $86 \%$ in non-germinated seeds in comparison to $14 \%$ in embryonal end. In case of germinated seeds, embryonal end and upper surface had 71\% and $30 \%$ sporulation, respectively.

Table 3. Detection of F. moniliforme and other fungi associated with different categories of seed (Var. BR1).

\begin{tabular}{l|c|c}
\hline Seed grade & $\begin{array}{c}\text { F. moniliforme } \\
(\%)\end{array}$ & $\begin{array}{c}\text { Other fungus* } \\
(\%)\end{array}$ \\
\hline Apparently healthy & $17.50 \mathrm{c}$ & $6.00 \mathrm{c}$ \\
Discolored filled grain & $31.50 \mathrm{~b}$ & $10.08 \mathrm{a}$ \\
Discolored unfilled grain & $74.75 \mathrm{a}$ & $9.50 \mathrm{ab}$ \\
Unfilled grain (normal) & $30.50 \mathrm{~b}$ & $7.42 \mathrm{bc}$ \\
\hline
\end{tabular}

Means followed by the same letter(s), in a column, did not differ at the $5 \%$ level of significance by LSD. Trichoconis padwikki, Curvularia spp. and Alternaria sp. 
Table 4. Percent seeds having sporulation of $F$. moniliforme on germinating and non-germinating filled rice seeds.

\begin{tabular}{l|c|c|c|c}
\hline \multirow{2}{*}{ Variety } & \multicolumn{2}{|c|}{ Embryonal end } & \multicolumn{2}{c}{ Upper surface } \\
\cline { 2 - 5 } & $\begin{array}{c}\text { Non-germinated } \\
\text { seeds (\%) }\end{array}$ & $\begin{array}{c}\text { Germinated seeds } \\
(\%)\end{array}$ & $\begin{array}{c}\text { Non-germinated } \\
\text { seeds (\%) }\end{array}$ & $\begin{array}{c}\text { Germinated seeds } \\
(\%)\end{array}$ \\
\hline BR1 & 16 & 76 & 84 & 25 \\
BRRI dhan44 & 12 & 66 & 88 & 34 \\
Mean & 14 & 71 & 86 & 30 \\
\hline
\end{tabular}

Based on 100 non-germinating seeds and 400 germinating seeds with F. moniliforme of each variety.

Seed to seedling transmission of Fusarium moniliforme. Table 5 presents the transmission of $F$. moniliforme from seed to seedlings. Percent transmission was higher in sterilized soil than in non sterilized soil for both the varieties. In case of BR1, the highest $37.14 \%$ transmission was observed when pre-sprouted seeds were sown on puddled soil. The lowest $8.57 \%$ transmission was recorded when dry seeds sown in the moist soil. Dry seeds sown on puddled soil had $24.76 \%$ transmission of $F$. moniliforme. Similarly, for non-sterilized soil, transmission rate was $26.66 \%$ when pre sprouted seeds were sown on puddled soil. It was $17.14 \%$ and $6.72 \%$ for dry seeds sown on puddled soil and dry seeds sown under the moist soil, respectively. Similar trends of rate of transmission of F. moniliforme from seeds to seedlings was observed in case of BRRI dhan 44 . The \% transmission of F. moniliforme was more in sterilized soil than that of nonsterilized one. The transmission of $F$. moniliforme in sterilized and non-sterilized soil was $23.49 \%$ and $16.85 \%$ respectively in BR1. It was $26.01 \%$ and $18.96 \%$ in sterilized and nonsterilized soil of BRRI dhan44.

Table 5. Transmission of F. moniliforme from seed to seedlings in different seeding methods.

\begin{tabular}{|c|c|c|c|c|c|}
\hline \multirow{3}{*}{ Seeding method } & \multicolumn{4}{|c|}{ Transmission (\%) } & \multirow{3}{*}{ Mean } \\
\hline & \multicolumn{2}{|c|}{ BR1 } & \multicolumn{2}{|c|}{ BRRI dhan 44} & \\
\hline & $\begin{array}{l}\text { Sterilized } \\
\text { soil }\end{array}$ & Non-sterilized soil & $\begin{array}{l}\text { Sterilized } \\
\text { soil }\end{array}$ & Non-sterilized soil & \\
\hline $\begin{array}{l}\text { Dry seed on } \\
\text { puddled soil }\end{array}$ & $24.76 \mathrm{~b}$ & $17.14 \mathrm{~b}$ & $28.32 \mathrm{~b}$ & $19.51 b$ & 22.43 \\
\hline $\begin{array}{l}\text { Sprouted seed on } \\
\text { puddled soil }\end{array}$ & $37.14 \mathrm{a}$ & $26.66 \mathrm{a}$ & $39.96 \mathrm{a}$ & $31.71 \mathrm{a}$ & 33.86 \\
\hline $\begin{array}{l}\text { Dry seed under } \\
\text { moist soil }\end{array}$ & $8.57 \mathrm{c}$ & $6.72 \mathrm{c}$ & $9.75 c$ & $5.68 c$ & 7.68 \\
\hline Mean & 23.49 & 16.84 & 26.10 & 18.96 & \\
\hline
\end{tabular}

Means followed by same letter, in a column, did not differ at the $5 \%$ level of significance by LSD. 


\section{DISCUSSION}

Fusarium moniliforme Sheld (bakanae pathogen) occurs in almost all rice growing countries of the world including Bangladesh. Fungal contamination of rice seed samples with this pathogen is a major problem for farmers, in many developing countries. It is proved to be primarily seed-borne and high level of incidence has been found in rice seed samples (Singh and Sunder, 1997).

The findings of the present study confirmed the occurrence of $F$. moniliforme associated with rice seed samples in Bangladesh. This is in accordance with the findings of Fakir et al. (1990). They reported $F$. moniliforme was more prevalent in 58 and 59 seed samples, out of 60 samples of two rice varieties. Mia and Mathur (1983) tested seed health of 75 seed samples from different parts of Bangladesh and observed more than $90 \%$ samples infected. Present study reveals that the average infections in three different seasons were 15.35, 14.77 and 17.68\%, respectively. Earlier reports from Bangladesh are in accordance with the present findings (Rahman, 2002, Uddin, 2003, Momotaz, 2005). According to Uddin (2003) F. moniliforme was found in seed at a range of $0.6-5.2 \%$. Incidence of $F$. moniliforme varied with respect to the source of seeds. Farmers' saved seeds showed higher seed infection than those from BADC seeds. This situation prevailing in the country may be due to ignorance of farmers' about seed borne diseases and their poor storage condition. Previously, Islam et al. (1994) and Chowdhury et al. (2013) mention that percent seed infection in farmers' seeds was higher than BADC seeds. From the results of the present study it appeared that location has little influence on the infection of $F$. moniliforme for BADC seeds. Sporulation of the pathogen occurred either from the embryonal end alone or from the entire seed surface of both germinating and nongerminating seeds. Sporulation of $F$. moniliforme on embryonal end was much higher in germinating seed than that of the non-germinating seeds. The result is supported by the observation of Agarwal et al. (1989). They stated that F. moniliforme mainly harbored in the embryo. Another important observation made by Chung and Lee (1983) is that sporulation of Pyricularia oryzae was confined to the embryonal end of rice seeds. It is well known that the embryonal end of rice seeds has high protein content and this may possibly enhance the sporulation of $F$. moniliforme (Manandhar et al., 1998). When the seeds are dead, the fungus can utilize the whole seeds as a substrate, as suggested by Limonard (1968), who observed abundant sporulation of Fusarium, Helminthosporium and Septoria on dead seeds of different cereals. The embryonal end of rice seeds as a preferred site for F. moniliforme is important in nature since the fungus gets easy and quick access to the shoot coming out from the seed (Manandhar et al., 1998). Our investigation reveals that high rate of seed transmission of $F$. moniliforme occurs in pre-sprouted seed. During soaking of infected seeds, the spore released into water and again infect another seed, as a result the incidence of $F$. moniliforme increased in pre sprouted seed (Karov et al. 2008; Martin 2008). Low rate of transmission was found when the seeds were sown in the soil. From these results, it seems that the fungus needs aerobic condition to survive, sporulations and infect the seedlings. The results are in consistent with the observation made by Martin (2008). He stated that bakanae pathogen reproduced rapidly in the presence of oxygen. Similarly, Manandhar et al. (1998) reported that transmission of Pyricularia oryzae rarely occurred when the seeds were completely covered with the soil. The transmission was lower when seed sown in non-sterilized soil than seeds sown in sterilized soil. The reason is that the presence of antagonistic soil microorganism might have restricted seed transmission of pathogen.

Prevalence and Transmission of Fusarium moniliforme 


\section{CONCLUSION}

The results of the present study reveal that seed borne $F$. moniliforme was present in all of the seed samples collected from different locations and sources in a varied level and infection was found high in the farmers saved seed. Although test to find out the percent of infection of this pathogen in other varieties were not conducted. While in certain instance it occurred in trace level but under suitable environmental condition it may create the disease in epidemic form. Furthermore, results also reveal that the pathogen successfully transmitted from seed to seedlings. Most of the farmers in Bangladesh used their own saved seeds. Therefore, as a seeding material, the seed health status of farmers saved seeds need to be improved.

\section{AUTHORS CONTRIBUTION}

MSH, MAA and MAIK generated idea; coordinated the experiment; developed methodology; provided scientific insights, gathered data; carried out analysis and synthesis and did the writings for all versions of the manuscript. SM carried out some analysis and synthesis; All authors read and approved the final manuscript.

\section{ACKNOWLEDGEMENT}

The authors gratefully acknowledge to the human resource development programme of BARC, Farmgate, Dhaka for providing PhD fellowship to conduct the experiment smoothly.

\section{DECLARATION OF INTERESTS}

The authors declare that they have no known competing financial interests or personal relationships that could have appeared to influence the work reported in this paper.

\section{REFERENCES}

Agarwal, P C, C N Mortensen and S B Mathur. 1989. Seed borne diseases and Seed Health Testing of Rice. National
Bureau of Plant Genetics Resources, Pusa Campus, New Delhi, India. pp.106.

Chung, H S and C U Lee. 1983. Detection and transmission of Pyricularia oryzae in germination rice seed. Seed Science and Technology, 11:625-637.

Chowdhury, M M H, I Hossain, M R A Mondol, H Mahmud and S Kayser. 2013. Effect of seed sources and seed treatments on germination and health of T. Amna rice in Bangladesh. Int. J. Bioresearch, 15(1):7-11.

Fakir, G A, M R Islam and M F Islam. 1990. Survey on the health status of jute and rice seeds of farmers of Sadar Thana, Mymensingh. BAU. Research Progress, $4: 42-47$.

Islam, M R, A Ali and M A T Mia. 1994. Survey on seedborne pathogens of rice in fifteen districts of Bangladesh. Bangladesh Journal of Plant Pathology, 10(1\&2): 23-26.

ISTA (International Seed Testing Association). 2000. International Seed Testing Association, International rules for seed testing. Seed Science and Technology, 335.

Kim, C K. 1981. Ecological studies of bakanae disease of rice caused by Gibberella fujikorai. Korean Journal of Plant Protection, 20:146-151.

Karov, I K, S K Mitrevand E D Kostadinovaska. 2008. Gibberella fujikuroi (Sawada) Wollenweber. The new parasitical fungus on rice in the republic of Macedonia: In: Proceedings of National Science, Matica Srpska Novi Sad, 116:175-182.

Limonard, T. 1968. Ecological aspects of seed health testing. Proceedings of International Seed Testing Association, 33:343-513.

Latif, M A, M A T Mia and M Hossain. 2006. Yield loss, integrated management approaches and development of a quick screening method of bakanae disease of rice in Bangladesh (In abstract). $2^{\text {nd }}$ International rice congress, October 9-13, 2006, New Delhi, India, p. 409.

Martin, K. 2008. Don't be fooled by this disease. Use cultural practices, seed treatment to reduce Bakanae in fields. Available at: http://agronomy.ucdavis.edu/ uccerice/.

Mia, M A T and S B Mathur. 1983. Study on seed myciflora on rice in Bangladesh. Bangladesh Seed Research, 11(2):254-257.

Miah, S A and A K M Shahjahan. 1987. Mathe dhaner rog nirnoy o tar protiker (In Bangla). Bangladesh Rice Research Institute, Gazipur, Bangladesh. 60p.

Miva, S P, A T Modi and T Mabhaudhi. 2017. Interactive effects of simulated hail damage and plant density 
on maize seed quality. Seed Sci. Technol., 45(1):100111.

Manandhar, H K, H J L Jorgenson and V S Petersen. 1998. Seed-borne infection of rice by Pyricularia oryzae and its transmission to seedlings. Plant Disease, 82(10) :1093-1099.

Momotaz, R. 2005. Development and standardization of screening method for resistance to bakanae disease of rice. Unpublished M S Thesis, Department of Plant Pathology, Sher-E- Bangla Agricultural University, Dhaka-1207, Bangladesh.

Nath, R, P Neergaard and S B Mathur. 1970. Identification of Fusarium species on rice seeds as they occur in blotter test. Proceedings of International Seed Testing Association, 35:121-141.
Rahman, M M. 2002. Effect of farmer's storage process in relation to seed quality and seed-borne fungi of rice (BR1). Unpublished MS Thesis. Department of Plant Pathology, Bangladesh Agricultural University, Mymensingh-2202, Bangladesh.

Singh, R and S Sunder. 1997. Foot rot and bakanae of rice: Retrospects and Prospects. International Journal of Tropical Plant Disease, 15:153-176.

Uddin, M J. 2003. The quality of farmers stored rice seed of Begumgonj upazila. Unpublished MS Thesis, Department of Plant Pathology, Bangladesh Agricultural University, Mymensingh-2202, Bangladesh.

Winter, W E, S B Mathur and P Neergaard. 1974. Seedborne organisms of Argentina: A survey. Plant disease Rept., 58:507-511. 